\title{
NUMERICAL AND EXPERIMENTAL STUDY OF A TWO-STAGE SAVONIUS WIND TURBINE
}

\author{
L. B. Kothe, \\ and A. P. Petry \\ Universidade Federal do Rio Grande do Sul \\ Departamento de Engenharia Mecânica \\ Laboratório de Mecânica dos Fluidos - LMF \\ Rua Sarmento Leite, 425, 90050-170 \\ Porto Alegre, Rio Grande do Sul, Brasil \\ leonardo.kothe@ufrgs.br \\ adrianep@mecanica.ufrgs.br \\ Received: June 15, 2018 \\ Revised: August 21, 2018 \\ Accepted: February 12, 2019 \\ ABSTRACT \\ This article presents a numerical and experimental study of vertical axis \\ wind turbine performance comparison involving a two-stage Savonius rotor \\ with similar parameters. The experimental study is conducted in the \\ aerodynamic tunnel at the Fluid Mechanics Laboratory of the Federal \\ University of Rio Grande do Sul. The aerodynamics rotors are \\ manufactured by 3D prototyping technique. Numerical simulations are \\ performed using the Finite Volumes Method performed by the solution of \\ the Reynolds Averaged Navier-Stokes (RANS) and continuity equations \\ using the SST $k$ - $\omega$ turbulence model. The numerical domain is modeled in \\ order to maintain the same characteristics of the experimental model. The \\ mesh quality is evaluated through the GCI (Grid Convergence Index) \\ method. The static and dynamic torque coefficients and the power \\ coefficients are compared. The tests are made without blockage corrections \\ due to the small blockage ratio from $7.5 \%$. Results show that the turbine has \\ a positive static torque coefficient for any rotor angles. The dynamic torque \\ reaches the maximum value for a tip speed ratio $(\lambda)$ of 0.2 for the \\ experimental and numerical cases. The relative difference between the \\ numerical simulations and the experimental results are between $3.8 \%$ and \\ $13.4 \%$. \\ Keywords: two-stage Savonius rotor; experimental study; numerical \\ simulation
}

\section{NOMENCLATURE}

A area, $\mathrm{m}^{2}$

c bucket chord, $\mathrm{m}$

$\mathrm{C}_{\mathrm{P}}$ power coefficient

$\mathrm{C}_{\mathrm{T}}$ torque coefficient

$\mathrm{D}$ turbine diameter, $\mathrm{m}$

$\mathrm{d}_{\mathrm{ep}} \quad$ diameter of the end plates, $\mathrm{m}$

$\mathrm{F}$ force, $\mathrm{N}$

g gravity, $\mathrm{m} / \mathrm{s}^{2}$

$\mathrm{h}_{1} \quad$ turbine stage height, $\mathrm{m}$

$\mathrm{h}_{2} \quad$ thickness of the intermediate plate, $\mathrm{m}$

$\mathrm{H}$ turbine height, $\mathrm{m}$

$\mathrm{k}$ turbulent kinetic energy, $\mathrm{J} / \mathrm{kg}$

$\mathrm{m}_{\text {bal }} \quad$ balance mass, $\mathrm{kg}$

$\mathrm{m}_{\mathrm{l}} \quad$ load mass, $\mathrm{kg}$

n angular velocity, $\mathrm{rad} / \mathrm{s}$

$\mathrm{P}$ power, $\mathrm{W}$

$\mathrm{r}$ rotor radius, $\mathrm{m}$

$\mathrm{r}_{\mathrm{sh}} \quad$ shaft radius, $\mathrm{m}$

$t \quad$ thickness of the buckets, $m$

$t_{\text {ep }} \quad$ thickness of the end plates, $m$

$\mathrm{t}_{\mathrm{st}} \quad$ string thickness, $\mathrm{m}$

$\mathrm{T}$ rotor moment, N.m

$\mathrm{V}_{\infty} \quad$ undisturbed air flow velocity, $\mathrm{m} / \mathrm{s}$

$\mathrm{u} \quad$ velocity flow, $\mathrm{m} / \mathrm{s}$

u' velocity fluctuation, $\mathrm{m} / \mathrm{s}$

$\bar{u} \quad$ average velocity, $\mathrm{m} / \mathrm{s}$

\section{Greek symbols}

$\Delta \mathrm{t} \quad$ time step, $\mathrm{s}$

$\Delta \theta \quad$ angular step, ${ }^{\circ}$

$\varepsilon \quad$ viscous dissipation rate, $\mathrm{m}^{2} / \mathrm{s}^{3}$

$\mu \quad$ air dynamic viscosity, $\mathrm{kg} /(\mathrm{m} . \mathrm{s})$

$v \quad$ air kinematic viscosity, $\mathrm{m}^{2} / \mathrm{s}$

$\theta \quad$ angular position, ${ }^{\circ}$

$\rho \quad$ atmospheric air density, $\mathrm{kg} / \mathrm{m}^{3}$

$\lambda$ tip speed ratio of the rotor

$\omega$ specific dissipation rate, $\mathrm{s}-1$

$\tau \quad$ Reynolds stress

\section{Subscripts}

$\begin{array}{ll}\text { bal } & \text { balance } \\ \text { ep } & \text { end plates } \\ \text { l } & \text { load } \\ \text { opt } & \text { optimal } \\ \text { sh } & \text { shaft } \\ \text { st } & \text { string } \\ \text { P } & \text { power } \\ \text { T } & \text { torque } \\ 1 & \text { stage 1 } \\ 2 & \text { stage 2 } \\ \infty & \text { free stream }\end{array}$

Superscripts

' fluctuation average 


\section{INTRODUCTION}

In recent years, there has been much discussed the need for renewal the energy matrix in the world with a greater decentralization. For this, new forms of energy production are proposed in order to reduce environmental pollution, exhaustion of nonrenewable sources and global warming. Among the main renewable resources energy production are wind power, which is then the subject of studies and generally used in urban and rural areas.

Responsible to transform into mechanical energy to kinetic energy of the wind, the wind turbines has become a major means of alternative and renewable energy production. These types of turbines are commonly divided between horizontal and vertical axis. In this article will be studied a vertical axis wind turbine, which it is emphasized the Savonius type, presenting a simple construction when compared with other types (Burton et al., 2011).

The Savonius wind rotor, an invention developed and patented by Sigurd J. Savonius in the 1920 s, presents its disposition in the " $S$ " form along its vertical axis which the rotation occurs mainly due to the drag force provided by the wind in its concave and convex buckets (Savonius, 1930). This type of rotor is commonly used for pumping stations and driving force due to its high torque developed and low angular velocity. However, changes such as an increase in its aspect ratio can be made, providing higher speed and increasing generation of power (Savonius, 1930; Akwa et al., 2012a; Fujisawa, 1992; Saha et al., 2008; Kamoji et al., 2009), also could be installed in combination with other types of turbines or other types of generation, such as a photovoltaic cell.

Studies are conducted to determine characteristics of the Savonius turbines as experimental studies and CFD (Computational Fluid Mechanics). Akwa et al., (2012b) created a review study on the performance of Savonius wind turbines. Introducing the main parameters of this type of turbine, as the aspect ratio, the overlap ratio, the end plates effect and the number of stages and blades, the authors selected a set of important information for achieving a better design of a rotor for different types of conditions. Fujisawa (1992) conducted an experimental study was conducted with a comparison between different overlap ratio for a rotor with and without rotation. The experiments were performed for four rotors with different overlap ratios ranging between 0 and 0.5 . For the static torque, the performance was improved by increasing the overlap ratio, especially on the return bucket due to the effect of pressure recovery by flow through this overlap. For the rotation rotor the peak values of the torque and power coefficients was achieved for an overlap ratio of 0.15. Damak et al. (2013) presented an experimental study involving a Savonius turbine with $180^{\circ}$ twist buckets. In a wind tunnel with an open section of $0.4 \times 0.4 \mathrm{~m}$ was installed the rotor where the experiment was carried out for a flow velocity of $6 \mathrm{~m} / \mathrm{s}, 7.5 \mathrm{~m} / \mathrm{s}, 8.8 \mathrm{~m} / \mathrm{s}$ and $11.1 \mathrm{~m} / \mathrm{s}$. The authors shown the relationship between the variation about the Reynolds number and the overlap ratio on the performance of the helical Savonius rotor, also showing improved performance over the helical rotor compared with a conventional rotor. Saha et al. (2008) conducted tests in a wind tunnel to get results on the aerodynamic performance of a rotor with one, two and three stages. The authors mixed the format of the buckets between semicircular and twist, the number of buckets and the use of valves on the buckets. In total 14 types of wind rotors with identical aspect ratios and with same projected area were manufactured. The test velocity was varied between 6 and $11 \mathrm{~m} / \mathrm{s}$. The main observations of the authors is that the optimal number of buckets found has two, both for one, two or three stages. Two-stage rotors had higher power coefficients with respect to one and three stage rotors.

In recent years, computational solutions were used by authors (Akwa et al., 2012a; Menet and Bourabaa, 2004; Altan and Atilgan, 2010). Menet and Bourabaa (2004) checked the behavior of a rotor for Reynolds values between $1 \times 10^{5}$ and $5 \times 10^{5}$. For this range of values, there is an increase in performance coefficients for almost the entire range, with the highest values obtained for the largest Reynolds values. Altan and Atilgan, (2010) conducted experiments in a numerical and experimental form to improve the low performance levels of the Savonius rotors. Tests were made for the rotor with different types of curtain and without the curtain. A considerable increase has been seen in the rotor performance with the use of curtain at the end of the study. Akwa et al. (2012a) simulated Savonius rotors with different overlap ratio. The ratios were varied at $0.0,0.15,0.3,0.45$ and 0.6. Among the analyzed settings, the best performance was obtained for 0.15 which a power coefficient of 0.3161 for a tip speed ratio of 1.25 . According to the authors, a space between the buckets permits the passage of air from the forward to return bucket, increasing the pressure of the back side of the concave bucket and reducing drag force on this part of the rotor.

According to these studies, it is possible to analyze that the performance of Savonius rotors can be improved. It is also possible to observe a certain discrepancy between numerical and experimental results due the many differences found between the used methodologies. The aims of this work are to carry out a comparative analysis between the numerical and experimental forms in the performance of a two-stage turbine. Validating these numerical method will be possible to describe the behavior of turbines in real situations using CFD, to predict the open field behavior and uses this tool for optimization studies for different types of turbines. Experimental data are also published in details to 
provide information for other researchers. Furthermore, it is possible to reduce the number of experimental tests, reducing manufacturing costs.

\section{METHODOLOGY}

\section{Experimental Model}

To make possible a comparison of numerical and experimental tests, the Savonius turbine design is the same for both cases. The two-stage Savonius turbine is first created through a CAD software and after manufactured by 3D prototyping technique. The numerical simulations are performed with the geometry created by 3D CAD.

Fig. 1 shows the dimensions of the Savonius turbine. The height $(H)$ is $0.380 \mathrm{~m}$, the rotor diameter $(D)$ is $0.095 \mathrm{~m}$ and the thickness of the buckets is $0.005 \mathrm{~m}$, so that the maximum frontal area projected by the rotor is $0.0361 \mathrm{~m}^{2}$, not requiring blockage effect correction as the cross-sectional area of the test section that has $1 \mathrm{~m}^{2}$. The buckets overlap corresponding to $15 \%$. Overlaps with values between $10 \%$ and $30 \%$ of the chord give good results for the average power ratio in operation (Akwa et al., 2012b). Table 1 describes all the parameters necessary for manufacturing.

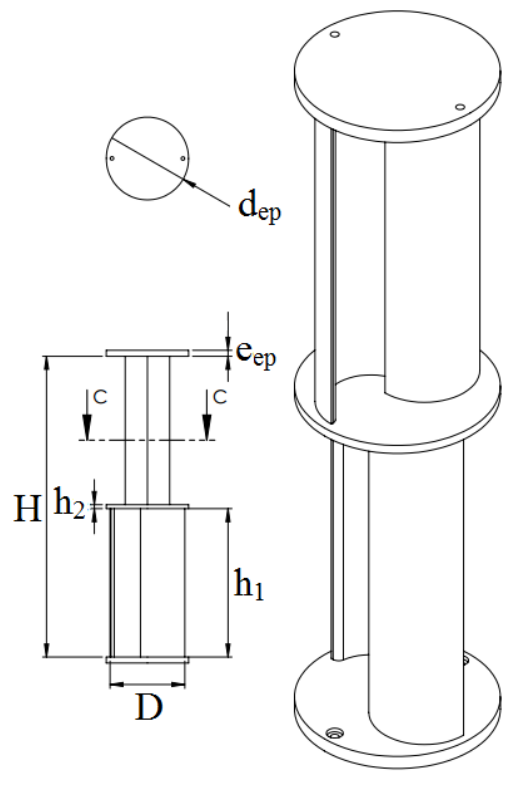

Figure 1. Two-stage Savonius rotor.

Table 1. Chosen parameters for the turbine.

\begin{tabular}{|c|c|}
\hline Parameters & Dimensions [m] \\
\hline$t$ & 0.005 \\
\hline$c$ & 0.0513 \\
\hline$h_{1}$ & 0.1875 \\
\hline$h_{2}$ & 0.005 \\
\hline
\end{tabular}

The diameter of the end plates $\left(d_{e p}\right)$ is $0.1045 \mathrm{~m}$, and their thickness $(t)$ is $0.0075 \mathrm{~m}$. According to
Akwa et al. (2012b), end plates improves the aerodynamic performance of the rotor, because its presence prevents air leakage in the concave part of the buckets to the external flow, while maintaining the differential pressure in the concave and convex parts of bucket.

The aspect ratio adopted, given by the height of the rotor divided by its diameter, is 4.0. The use of high aspect ratios turbines tend to improve turbine efficiency (Alexander and Holownia, 1978).

\section{Numerical Methodology}

Numerical simulations of the Savonius rotor type are conducted in the commercial software ANSYS ${ }^{\circledR} /$ Fluent ${ }^{\circledR}$ using Finite Volumes Method. Finite Volumes Method uses the integral form of the conservation equations as its starting point (Ferziger and Peric, 2002). The solution domain is divided into a finite number of adjacent volumes control, and the conservation equations are applied to each volume control. An algebraic equation obtained for each volume control is solved iteratively [Patankar, (1980)].

The mass conservation equations and linear momentum are solved by the Reynolds Averaged Navier-Stokes (RANS) equations. Reynolds decomposition consisting in decomposes a scalar or vector variable in a medium temporal part and another as floating part (Wilcox, 1998). It is possible to make a replacement in the principle of mass conservation as

$$
\begin{gathered}
u(t)=\bar{u}+u^{\prime}(t) \\
\frac{\partial \bar{u}_{i}}{\partial x_{i}}=0
\end{gathered}
$$

For a given notation, with Reynolds decomposition for speed and pressure by the momentum principle, the balance equation of momentum is obtained that:

$$
\begin{gathered}
\frac{\partial \bar{u}_{i}}{\partial x_{i}}+\bar{u}_{j} \frac{\partial \bar{u}_{i}}{\partial x j}=-\frac{1}{\rho} \frac{\partial \bar{p}}{\partial x_{i}}+v \frac{\partial^{2} \bar{u}_{i}}{\partial x_{j} \partial x_{j}}-\frac{\partial}{\partial x_{j}} \overline{u_{i}^{\prime} u_{j}^{\prime}} \\
-\rho \overline{u_{i}^{\prime} u_{j}^{\prime}}=\tau
\end{gathered}
$$

According to Wilcox, (1998), the Reynolds stress represents the reciprocal of rate of change of momentum due to the velocity fluctuations. Its presence in Reynolds equation generates a closure problem caused when there are more unknowns than equations. To solve this problem, turbulence models are used. For this paper, the turbulence model SST $k-\omega$ is used. The SST $k-\omega$ model is a combination between the $k-\varepsilon$ and $k-\omega$ models. According to 
Menter et al. (2003), the formulation is based on a blending of functions, which ensures a proper selection of the $k-\omega$ and $k-\varepsilon$ zones without user iteraction.

For the time step value in each case it is used the equation:

$$
\Delta t=\frac{\Delta \theta \pi}{180^{\circ} \omega_{o}}
$$

\section{Computational Domain}

The simulations with stationary turbine, which are used for obtaining the mesh quality study and the coefficients of static torque, are steady and threedimensional. The simulations with rotating turbine are transient, three-dimensional, with a characteristic length of $0.07 \mathrm{~m}$ and a turbulence intensity of $2 \%$. For the case of the operating turbine, the simulation considers that the turbine performs three rotations and an angular displacement $(\Delta \theta)$ of $2.5^{\circ}$. Table 2 presents the TSR values with the respectively angular velocities and time step obtained for each case.

Table 2. Angular velocities and time step parameters for each TSR value.

\begin{tabular}{|c|c|c|}
\hline TSR & $\omega_{\mathrm{o}}[\mathrm{rad} / \mathrm{s}]$ & Time step [s] \\
\hline 0.2 & 32.0 & 0.0013635 \\
\hline 0.35 & 56.0 & 0.0007791 \\
\hline 0.5 & 80.0 & 0.0005454 \\
\hline 0.65 & 104.0 & 0.0004195 \\
\hline 0.8 & 128.0 & 0.0003408 \\
\hline 1.0 & 160.0 & 0.0002727 \\
\hline
\end{tabular}

Fig. 2 presented the computational domain and the boundary conditions. The length of the computational domain is $6 \mathrm{~m}$ and its cross area is 1 $\mathrm{m}^{2}$. The turbine is located downstream $2 \mathrm{~m}$ of the inlet region. This used computational domain is based on the aerodynamic tunnel dimensions used for the experimental tests. The interface region includes the simulated turbine located at the center horizontally and vertically in this region. Thus it is possible to impose an angular velocity in the turbine without changing the prescribed velocity inlet. The residuals used in the solutions are $10^{-4}$ for the steady simulations and $10^{-5}$ for transient simulations.

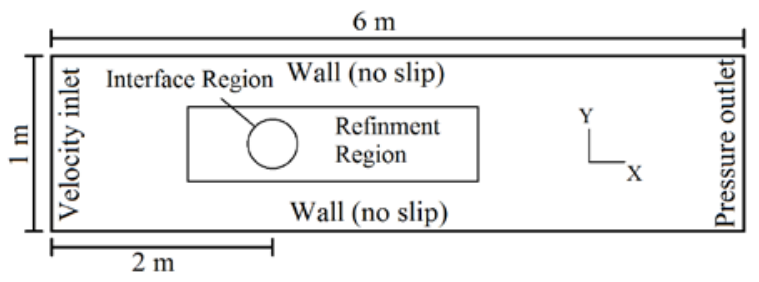

Figure 2. Computational domain.

The Reynolds number is calculated from:

$$
\mathrm{Re}=\frac{\rho D V_{o}}{\mu}
$$

For $D$ being the rotor diameter and $V_{o}$ the undisturbed flow velocity of $7.6 \mathrm{~m} / \mathrm{s}$, providing a Reynolds number of 49,640 for a temperature of $15^{\circ} \mathrm{C}$.

\section{Experimental Methodology}

Experimental tests are conducted in the open circuit aerodynamic tunnel at the Fluid Mechanics Laboratory of the Federal University of Rio Grande do Sul. To build the two-stage Savonius turbine is used the 3D printing method.

With the support of the Information Technology Center Renato Archer, the model is produced in polyamide (nylon), a material that has good strength, by a laser printer - Fig. 1. Due to small imperfections in the printed form, it is conducted a post process with the application of rubbing compound, sanding and painting process. Fig. 3 (a) shows the turbine before and after the finishing process. Fig. 3 (b) shows the support for fixing the turbine in the aerodynamic tunnel.

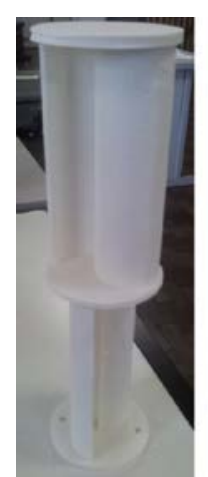

(a)

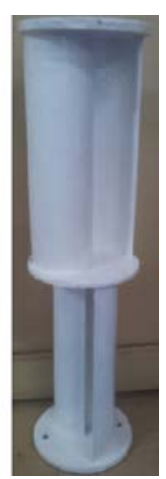

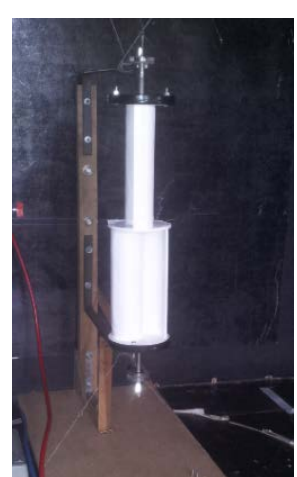

(b)
Figure 3. Savonius turbine model with two-stage: (a) printed model and (b) support.

The support consists in a vertical wooden pole with two horizontal bars, one upper and one lower, which are cable-stayed at the top and bottom of the tunnel in order to reduce vibrations due to the flow. Each bar has a rolling bearing, a shaft attached to the bearing, and an attached disk in the shaft end. Between these two discs is that the turbine is located where the turbine is located. To reduce the interference flow in the turbine, the support bracket is attached on the side wall of the aerodynamic tunnel.

The tests are conducted for an inlet velocity of $7.6 \mathrm{~m} / \mathrm{s}$ at the voltage source inverter set to $40 \mathrm{~Hz}$. The inlet velocity is checked by a Pitot tube situated in the test section upstream of $0.5 \mathrm{~m}$. After the velocity measurement is made the static torque measurement into a portable digital torque wrench Lutron, TQ-8800 model. The equipment is fixed at 
the bottom of the turbine shaft. The maximum range is $147.1 \mathrm{~N} / \mathrm{cm}$, having a "High" resolution of 0.1 $\mathrm{N} / \mathrm{cm}$, an accuracy range of $\pm 1.5 \%$ and a sampling rate of $0.125 \mathrm{~s}$. The turbine rotation is measured with a digital photo-tachometer, model MDT 2244B. This instrument operates in a range of $2.5 \sim 99,999 \mathrm{rpm}$ and has an accuracy of $\pm(0.05 \%+1 D)$.

Due to the need for more results and the fact that a dynamic torque meter having a high cost, it has been proposed to manufacture a simplified dynamic torque wrench similar to that used in the literature (Kamoji et al., 2009; Anbarsooz, 2016). For the assembly of the system is necessary to a string, a digital balance, a pulley and different portions of weights. The operating principle is to create a contact between the string and the axis of the turbine. Attached to one end of the string is a digital balance, with $5 \mathrm{~g}$ resolution. On the other side, the string pass by a pulley and go down to an outside region of the aerodynamic tunnel where this tip will be placed loads to function as a brake. Each load is weighed before the test in a digital precision balance, with 0.1 $\mathrm{g}$ resolution. With the rotor in operation, the rotation of the rotor will pull a load on the digital balance, and thus, the resultant force $(F)$ on the shaft can be calculated by

$$
F=\left(m_{b a l}-m_{l}\right) g
$$

Where $m_{b a l}$ is the mass measured in the balance; $m_{l}$ is the mass of the load hanging on the string and $g$ is the gravity. To determine the dynamic torque $(T)$, a multiplication of the resultant force by the radius $(r)$ of the shaft is made, the rotor radius is given by $r=r_{s h}+t_{s t}$ where $r_{s h}$ is the radius of the shaft with $0.005 \mathrm{~m}$ and $t_{s t}$ is the string thickness which has $0.0022 \mathrm{~m}$

$$
T=F r
$$

The angular velocity of the turbine $(n)$ is measured by means of a photo tachometer for the determination of the tip speed ratio and the estimated power $(P)$ as described

$$
P=\operatorname{Tn}
$$

In Fig. 4 a schematic picture of the photo tachometer and the system with the digital balance, the string and the load is displayed.

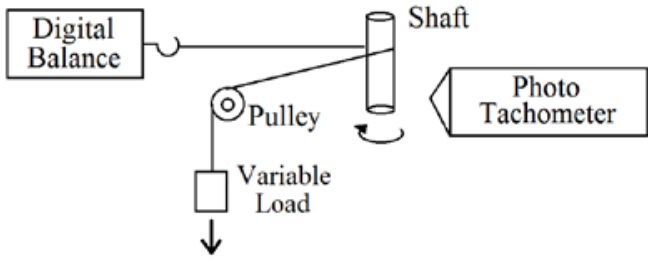

Figure 4. Dynamic torque wrench scheme.
Torque coefficient $\left(C_{T}\right)$ and power coefficient $\left(C_{P}\right)$ are determined by

$$
\begin{gathered}
C_{T}=\frac{T}{\frac{1}{2} \rho A V_{o}^{2} r} \\
C_{P}=\frac{T n}{\frac{1}{2} \rho A V_{o}^{3}}=C_{T} \lambda
\end{gathered}
$$

Where $T$ is the torque [N.m], $\rho$ is the air density $\left[\mathrm{kg} / \mathrm{m}^{3}\right], A$ is the turbine area $\left[\mathrm{m}^{2}\right], V_{o}$ is the flow velocity [m/s], $r$ is the radius of the turbine [m], and $\lambda$ the tip speed ratio.

A more accurate method for estimating the uncertainty of results was presented by (Kline and McClintock, 1953). His method is based on a detailed specification of the uncertainties of the different primary experimental measurements. Assuming a series of measurements is made and the uncertainty in each measurement can be expressed in the same form, one can then use them to calculate the uncertainty of the experiments (Holman, 2012).

\section{Mesh quality evaluation}

The mesh refinement of this paper is accomplished by the GCI method (Grid Convergence Index). The GCI is based on the generalized Richardson extrapolation involving comparison of discrete solutions in two different spacing meshes (Roache, 1994).

The application of GCI method is performed for three tetrahedral meshes with different refinements. Each mesh has an interface region, which has tetrahedral volumes, and a region which is called aerodynamic tunnel domain. The aerodynamic tunnel domain is invariant to the three meshes composed of $3,682,040$ volumes. The area near the turbine interface region has a different refinement as Table 3.

Table 3. Mesh refinement.

\begin{tabular}{|c|c|c|}
\hline Mesh & $\begin{array}{c}\text { Number of volumes in the } \\
\text { rotor region }\end{array}$ & $\begin{array}{c}\text { Total number of } \\
\text { volumes }\end{array}$ \\
\hline M1 & $6,078,091$ & $9,760,131$ \\
\hline M2 & $3,892,177$ & $7,574,217$ \\
\hline M3 & $2,405,627$ & $6,087,667$ \\
\hline
\end{tabular}

The results of the static torque coefficients for the three simulated meshes are shown in Table 4.

Table 4. Results of static torque coefficient for each simulated mesh.

\begin{tabular}{|c|c|}
\hline Mesh & Static Torque Coefficient \\
\hline M1 & 0.2400 \\
\hline M2 & 0.2515 \\
\hline M3 & 0.2791 \\
\hline
\end{tabular}


With the results of the static torque coefficient of each mesh (Table 4) is possible to apply the GCI method. The found value for the estimation of an exact solution of the torque coefficient for the finest meshes (M1 and M2), the convergence rates for the meshes and the value of asymptotic convergence are found is in Table 5.

Table 5. Application of the GCI method.

\begin{tabular}{|c|c|}
\hline Parameters & Values \\
\hline $\mathrm{C}_{\mathrm{T} \text {,estimated }}$ & 0.2345 \\
\hline $\mathrm{GCI}_{12}$ & $2.869 \%$ \\
\hline $\mathrm{GCI}_{23}$ & $8.414 \%$ \\
\hline Asymptotic convergence value & 0.954 \\
\hline
\end{tabular}

The application of the method indicates that for values close to 1 , the solution is within the range of asymptotic convergence. Based on the results shown in Table 4 it is possible to conclude that the solution is within the range of asymptotic convergence and the rotor static torque ratio is estimated to be 0.2345 , with a margin of error of $2.869 \%$. The mesh with the bigger refinement, with 9,760,131 volumes, is chosen for the work continuity.

\section{RESULTS AND DISCUSSION}

This chapter presents numerical and experimental results with an aim to comparing the two-stage Savonius turbine. Results of static torque coefficient and pressure fields with the static rotor, and tests for 5 different angular positions (Fig. 5) are presented. Also, are presented the results of dynamic torque coefficient and power coefficient with the turbine in motion.

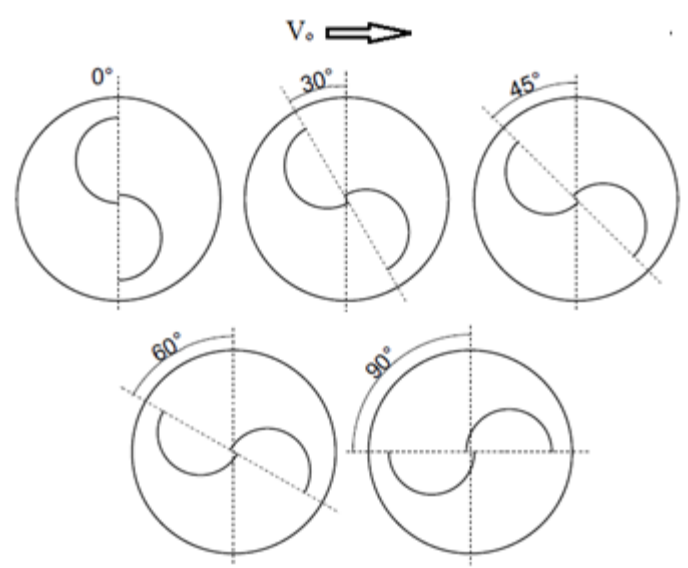

Figure 5. Turbine position during the static procedure.

\section{Results from static rotor}

For experimental measurements are considered the temperature inside the tunnel and the atmospheric pressure in the laboratory, being $24{ }^{\circ} \mathrm{C}$ and 754 $\mathrm{mmHg}$, respectively, resulting in an air density of
$1.17911 \mathrm{~kg} / \mathrm{m}^{3}$. The velocity inlet is $7.6 \mathrm{~m} / \mathrm{s}$. After the measurements for each turbine, by the positions of $0^{\circ}$, $30^{\circ}, 45^{\circ}, 60^{\circ}$ and $90^{\circ}$, its can make an average of static torque and its respective static torque coefficient are obtained for this flow velocity.

The experimental and numerical results are similar, where the experimental static $C_{T}$ ranged from 0.2984 to 0.3673 , however, due to uncertainties in experimental measurements, this difference can vary up to \pm 0.02806 . In the numerical case, the variation is from 0.2624 to 0.3984 . For this case there is a difference of maximum values, where for the experimental case the maximum static $C_{T}$ occurred for $60^{\circ}$, and for the numerical case the maximum value found is for $30^{\circ}$. This may be due to the numerical and experimental uncertainties. The maximum relative error is $12.65 \%$ but this difference can be varied due to measurement uncertainties. The results are shown in Table 6 , and a dispersion of the points with the respective uncertainty of experimental measurements can also be seen in Fig. 6. It is also possible to visualize that the behavior of the different angles on the static $C_{T}$ is similar in experimental and numerical analysis.

Table 6. Static torque coefficients.

\begin{tabular}{|c|c|c|c|c|}
\hline Angle & $\begin{array}{c}\text { Torque } \\
\text { [N.m] }\end{array}$ & $C_{T}$ (Exp.) & $\begin{array}{c}C_{T} \\
\text { (Num.) }\end{array}$ & $\begin{array}{c}\text { Relative } \\
\text { error [\%] }\end{array}$ \\
\hline $0^{\circ}$ & 0.01733 & $\begin{array}{c}0.2984 \\
\pm 0.0236\end{array}$ & 0.2607 & 12.65 \\
\hline $30^{\circ}$ & 0.02067 & $\begin{array}{c}0.3558 \\
\pm 0.0273\end{array}$ & 0.3984 & -11.97 \\
\hline $45^{\circ}$ & 0.02100 & $\begin{array}{c}0.3616 \\
\pm 0.0276\end{array}$ & 0.3478 & 3.80 \\
\hline $60^{\circ}$ & 0.02133 & $\begin{array}{c}0.3673 \\
\pm 0.0280\end{array}$ & 0.3526 & 4.00 \\
\hline $90^{\circ}$ & 0.01633 & $\begin{array}{c}0.2812 \\
\pm 0.0225\end{array}$ & 0.2624 & 6.69 \\
\hline
\end{tabular}

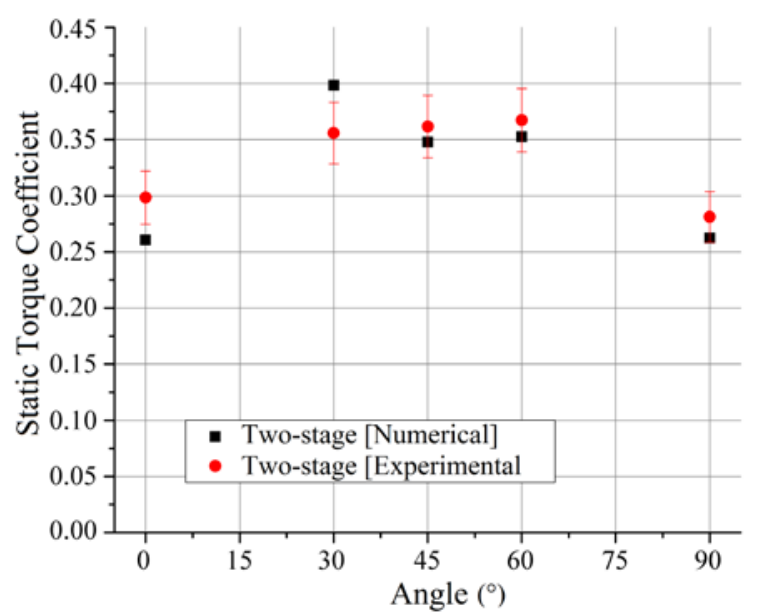

Figure 6. Static torque coefficient of the two-stage turbine for different angles.

Fig. 7 shows the selected planes used for the analysis. 


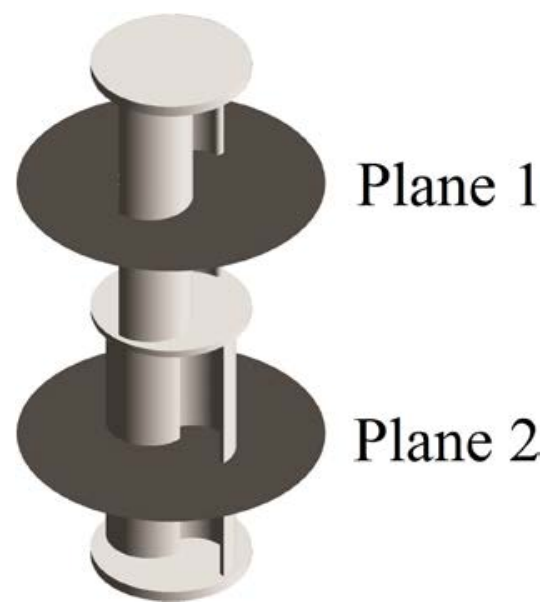

Figure 7. Selected planes for analysis.

Fig. 8 shows the pressure fields of numerical simulation for $0^{\circ}$ in the center position of each stage of the turbine region. The direction of flow from left to right is indicated. There is a large pressure differential in the concave and convex of the advancing bucket, due to the incidence of the flow making the rotor torque for this position dependent of the drag forces on the advancing bucket. In Fig. 9 it can be seen the plan with the flow velocity vectors with some recirculation points as the flow covers the buckets in concave sides and an adhered flow on the convex side of the buckets, due to the low pressure and consequently high speed.

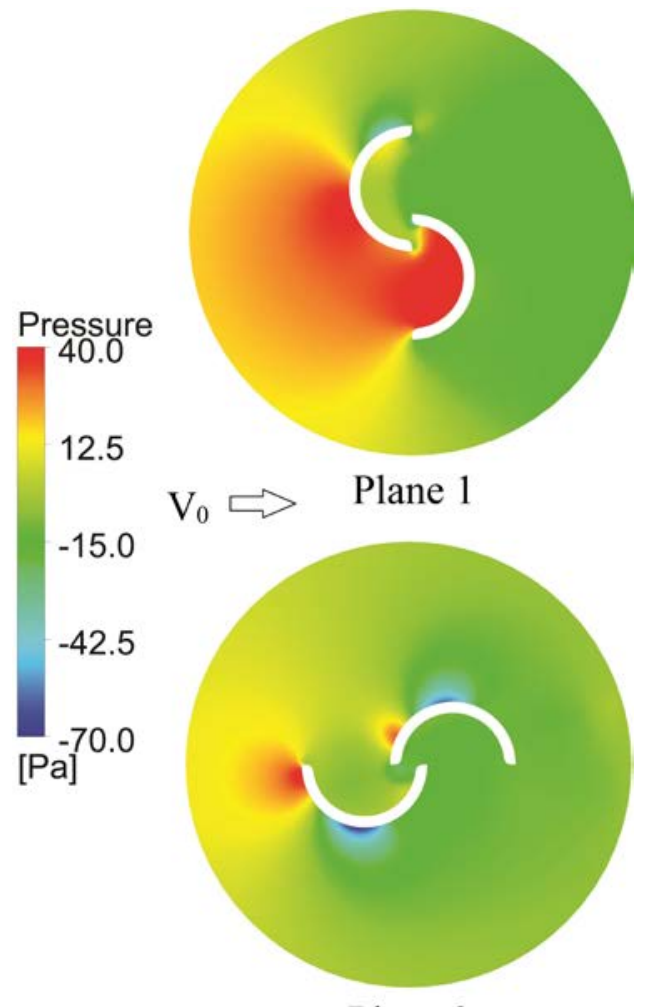

Plane 2

Figure 8. Pressure fields of the two-stage turbine for each stage.

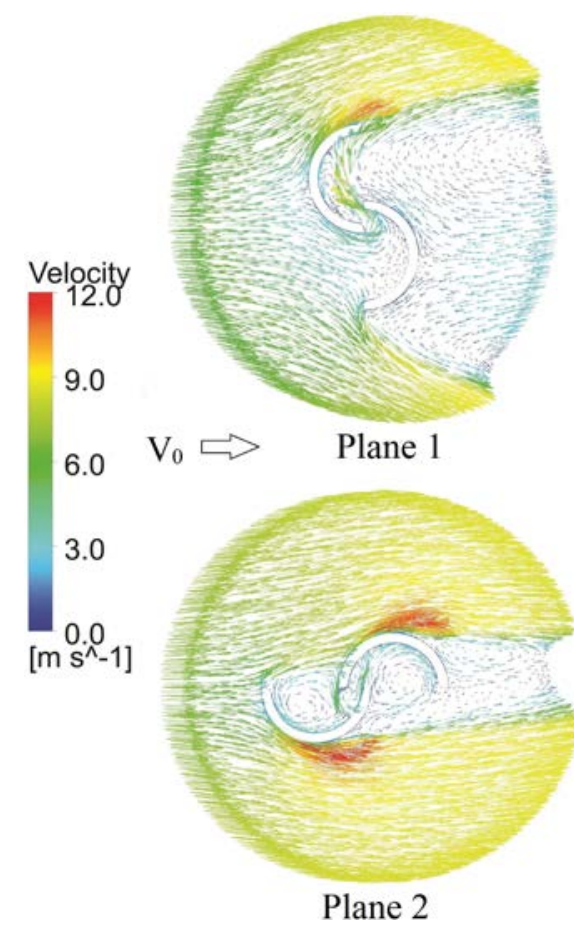

Figure 9. Velocity vectors of the two-stage turbine for each stage.

\section{Results with rotating rotor}

For the turbine rotation are shown the torque and power coefficients over a complete revolution of the turbine. Tests are performed to $\lambda$ values of 0.2 , $0.35,0.5,0.65,0.8$ and 1.0 , for numerical case, and $0.2,0.35,0.5$ and 0.65 for the experimental tests, where the values of $\lambda$ vary with the angular velocity of the turbine.

\section{Experimental results}

Measurements are made for a flow of $7.6 \mathrm{~m} / \mathrm{s}$. In this measurement, the turbine model rotates at $1,245 \mathrm{rpm}$, a value that is close to a tip speed ratio of 0.8 , as a consequence, it is possible to conduct measurement only for values of $\lambda$ lower than 1.0 , due to the measurement range of the torque wrench. For different loads, three measurements are performed, where results are shown in Table 7 . The measured results show that the torque increases with the reduction of the $\lambda$ value, generating a torque coefficient almost linear. The measured results showed that the torque decreases with the increase of the $\lambda$ value, generating an almost linear torque coefficient. This increase of torque, however, creates a value of $0.117 \pm 0.00938$ for the power coefficient, while in this measurement, its maximum value is found for $\lambda$ of 0.657 . The highest $C_{T}$ value is found for $\lambda$ of 0.208 , with a value of $0.299 \pm 0.02082$, but with a power coefficient of $0.062 \pm 0.00470,47.1 \%$ lower than the value obtained for a $C_{P}$ with a tip speed ratio of 0.657 . 
Table 7. Average values of the torque and power coefficients obtained in experimental measurements.

\begin{tabular}{|c|c|c|c|c|c|c|}
\hline$\lambda$ & $M_{\text {bal }}[\mathrm{kg}]$ & $m_{l}[\mathrm{~kg}]$ & $n[\mathrm{rad} / \mathrm{s}]$ & $T[\mathrm{~N} . \mathrm{m}]$ & $C_{T}$ & $C_{P}$ \\
\hline 0.657 & 0.1633 & 0.0175 & 105.14 & 0.01030 & $0.177 \pm 0.01330$ & $0.117 \pm 0.00938$ \\
\hline 0.504 & 0.198 & 0.0253 & 80.70 & 0.01222 & $0.210 \pm 0.01527$ & $0.106 \pm 0.00831$ \\
\hline 0.347 & 0.2567 & 0.0378 & 55.47 & 0.01546 & $0.266 \pm 0.01875$ & $0.092 \pm 0.00704$ \\
\hline 0.208 & 0.295 & 0.0493 & 33.30 & 0.01735 & $0.299 \pm 0.02082$ & $0.062 \pm 0.00470$ \\
\hline
\end{tabular}

\section{Numerical results}

The first results are presented regarding the torque curves for each simulation where they are determined according to the rotation angle of the turbine which ranges from $15^{\circ}$ to $15^{\circ}$. From Fig. 10 the torque is plotted for different values of $\lambda$.

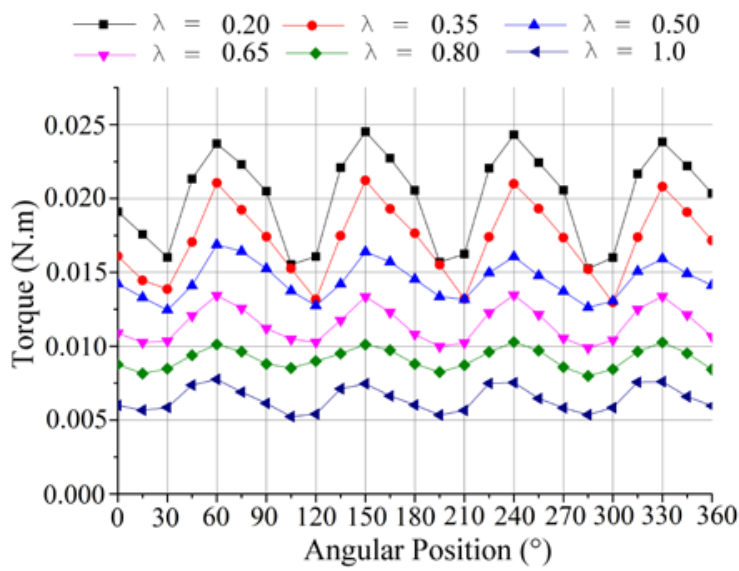

Figure 10. Variation of torque during one rotation of the two-stage turbine.

Now, it can be seen similar behavior for all cases represented by an oscillatory movement where in a complete rotation always occur four maximum peaks of torque (for angles of $60^{\circ}, 150^{\circ}, 240^{\circ}$ and $330^{\circ}$ ), and, consequently, the torque coefficient. It can be seen in the graph that with decreasing tip speed ratio value, the oscillation of torque during a rotation becomes higher and may be one of the factors that difficult the measurements of experimental torque.

Within the numerical solution is possible to obtain additional results to those obtained experimentally, where it is possible to analyze how the pressure profiles are formed on the buckets along the turbine rotation, and how these results are influenced by the pressure difference in the buckets. In addition to the pressure fields in the turbine, a velocity vector field is created in the central region of the turbine lower stage, where it is possible to understand the origin of the flow that reaches on turbines and how this flow behaves when passing through the turbines. Procedures like this make numerical simulations an interesting option for a better understanding of experimental results.

A brief analysis is made for the maximum torque point for a cycle of rotation of the turbine, for a $\lambda$ equal to 0.2 , as can be seen in Fig. 11. For an incidence angle of $60^{\circ}$ it can be seen a substantially constant pressure throughout the lower bucket, while the return bucket receives greater pressure only partially. To the upper stage the interference of pressure is lower since the bucket is almost in a lateral position in relation to the angle of incidence of the flow.

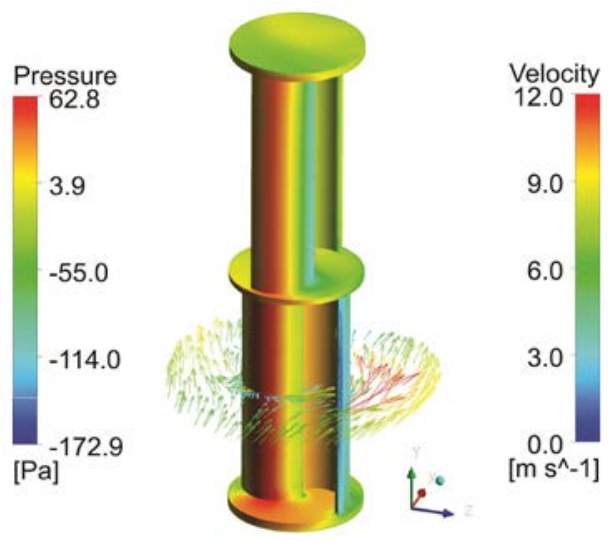

Figure 11. Velocity vector and pressure field for flow incidence of $60^{\circ}$.

In Fig. 12 is shown a chart where it is possible to observe that, by maintaining the same tip speed ratio value, the torque behaves similarly in all cases. However, by reducing the flow velocity, torque oscillation and intensity are also reduced. 3.4.

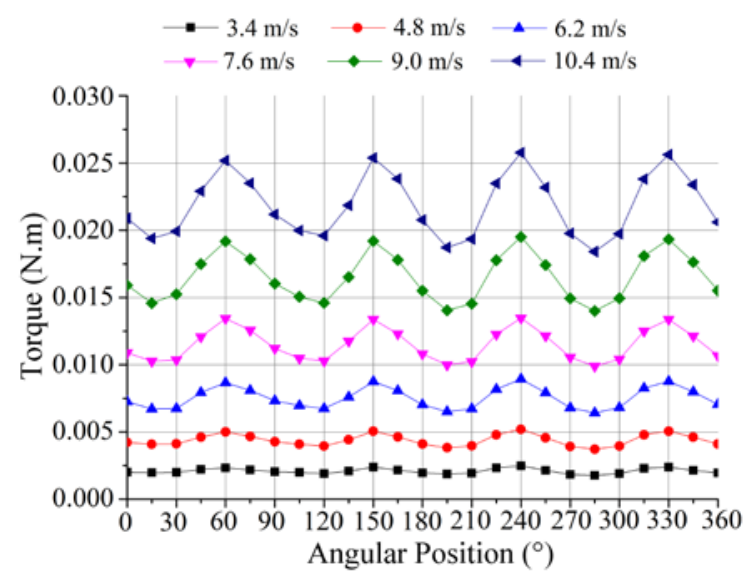

Figure 12. Variation of torque for a rotation of the two-stage turbine for different flow velocities with a $\lambda$ of 0.65 . 


\section{Experimental and numerical comparison}

Fig. 13 (a) shows a comparison of the dynamic torque coefficients obtained from simulations and experimental tests. As expected, it can be seen that for both cases, the higher $\lambda$ value, the lowest is the value of the torque coefficient. The largest percentage difference between the experimental test and the numerical case is approximately $10.8 \%$ for a $\lambda$ value of 0.5 . This percentage difference is the difference between the values found in the numerical and experimental tests divided by the value found in the torque coefficient in the experimental test.

Fig. 13 (b) shows the comparative of power coefficient for the experimental and numerical study. It is may be seen in this case that is a maximum of $C_{P}$ for the tip speed ratio of 0.65 where the value grows to this value and then decreasing again. The percentage difference for the $C_{P}$ curve is the same as the $C_{T}$ curve, where the greatest difference is also $10.8 \%$ for a $\lambda$ value of 0.5 , with a variation in the values due to measurement uncertainties.

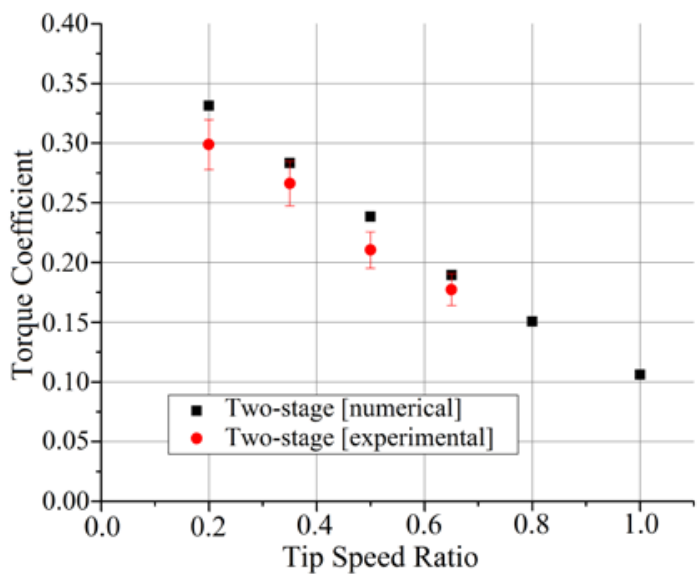

(a)

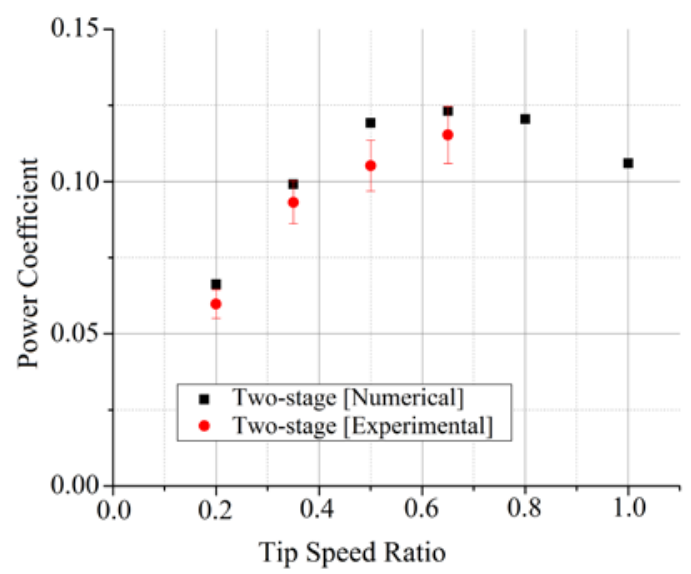

(b)

Figure 13. Comparison of the performance coefficients: (a) dynamic torque and (b) power.

The torque and power curves for numerical and experimental study are compared with the curves obtained experimentally by Kamoji et al. (2008) and simulated by Akwa et al. (2012a).

Kamoji et al. (2008) conducted an experimental study on Savonius rotor with one, two and three stages. The two-stage rotor showed an aspect ratio of 2.0 and an overlap of $15 \%$. From experimental tests, it is possible to create a power coefficient graph (Fig. 14(a)) for the two-stage turbine for different Reynolds numbers ranging from 48,900 to 97,800 . In Fig. 14(b) may be seen a comparison performed on the trend of the torque coefficient behavior obtained for different tip speed ratios of a 2D Savonius turbine wherein has different values of overlap ratio (Akwa et al., 2012a). However, due to its larger dimension, the Reynolds number is also simulated upper, being 433,500

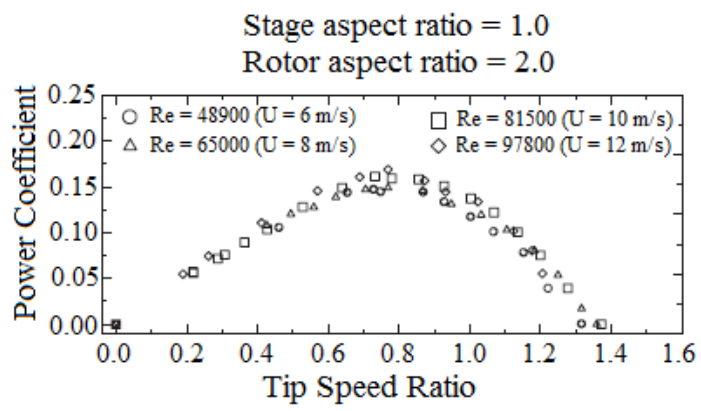

(a)

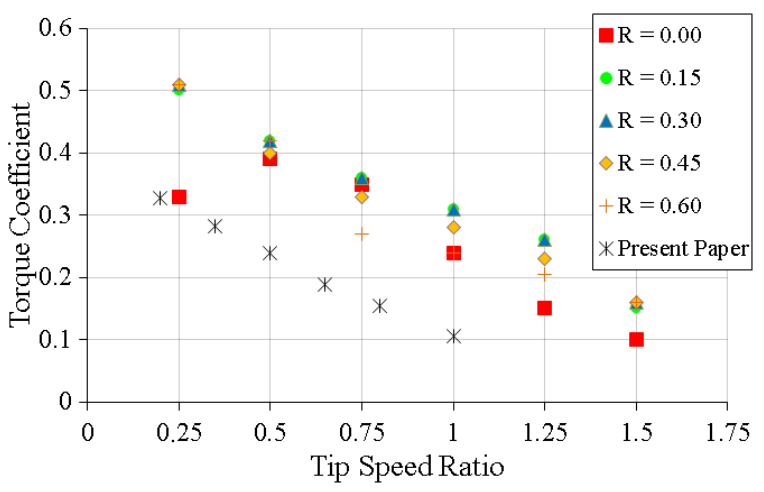

(b)

Figure 14. (a) power coefficient and (b) torque coefficient comparisons.

\section{CONCLUSIONS}

In this paper, it is possible to make a comparative analysis of numerical and experimental studies of a two-stage Savonius turbine manufactured by $3 \mathrm{D}$ prototyping method. The construction of the turbine is facilitated due to the fact that by 3D printing it is possible to create models with high complexity. It is also important for comparative studies, due to the necessity to generate models while maintaining the same dimensions and material only modifying its aerodynamic shape.

The experimental results were as expected. As there was no influence of the blockage effect, no 
corrections were necessary for the obtained values. The maximum value obtained for the torque coefficient was 0.3 for a $\lambda$ value of 0.2 . The maximum power coefficient was 0.114 for a $\lambda$ of 0.65 . However, due to the measurement uncertainties, these values can vary up to \pm 0.0208 for the maximum $C_{T}$ and \pm 0.0093 for the maximum $C_{P}$ values.

The result of the experimental tests and numerical simulations comparison is satisfactory. As can be seen, the percentage differences between the results for the power coefficient and the dynamic torque coefficient curves are in the order of $3.8 \%$ to $13.4 \%$. These differences may be related to the equipment and measurement uncertainties and also by numerical errors as inherent to the model used and rounding errors that produce approximate solutions. The used method for assessing the mesh quality, GCI, is significant in choosing the most appropriate mesh and quantification of the intrinsic error in using it. The experimental and numerical comparison showed that was possible to prove a good efficiency of the simplified dynamic torque wrench that was used.

The obtained numerical and experimental results increase the knowledge on the performance of Savonius wind turbines, showing the importance of the numerical methodology in this type of research, being also useful for future evaluation of actual turbines on site conditions.

\section{ACKNOWLEDGMENT}

Authors are grateful to Capes, Ministry of Education, Brazil and the CNPq National Council for Scientific and Technological Development, Ministry of Science, Technology and Innovation, Brazil, for the financial support of this research.

The valuable support from the Information Technology Center Renato Archer (https://www.cti.gov.br/en) and from the National Supercomputing Center - CESUP, Federal University of Rio Grande do Sul (http://www.cesup.ufrgs.br/) is here also gratefully acknowledged.

\section{REFERENCES}

Akwa, J. V., Silva Jr., G. A., and Petry, A. P., 2012a, Discussion on the Verification of the Overlap Ratio Influence on Performance Coefficients of a Savonius Wind Rotor Using Computational Fluid Dynamics, Renewable Energy, Vol. 38, pp. 141-149.

Akwa, J. V., Vielmo, H. A., and Petry, A. P., 2012b, A Review on the Performance of Savonius Wind Turbines, Renewable and Sustainable Energy Reviews, Vol. 16, pp. 3054-3064.

Alexander, A. J., and Holownia, B. P., 1978, Wind Tunnel Tests on a Savonius Rotor, Journal of Industrial Aerodynamics, Vol. 3, pp. 343-351.

Altan, B. D., and Atilgan, M., 2010, The Use of a Curtain Design to Increase the Performance Level of a Savonius Wind Rotors, Renewable Energy, Vol.
35, pp. 821-829.

Anbarsooz, M., 2016, Aerodynamic Performance of Helical Savonius Wind Rotors with $30^{\circ}$ and $45^{\circ}$ Twist Angles: Experimental and Numerical Studies, Journal of Power and Energy, Vol. 230, pp. 1-10.

Burton, T., Jenkins, N., Sharpe, D., and Bossanyi, E., 2011, Wind Energy Handbook, 2nd Edition, John Wiley \& Sons.

Damak, A., Driss, Z., and Abid, M. S., 2013, Experimental Investigation of Helical Savonius Rotor with a Twist of $180^{\circ}$, Renewable Energy, Vol. 52, pp. 136-142.

Ferziger, J. H., and Peric, M., 2002, Computational Methods for Fluid Dynamics, Springer, 3rd edition, Berlin, Heidelberg, New York, Barcelona, Hong Kong, London, Milan, Paris, Tokyo.

Fujisawa, N., 1992, On the Torque Mechanism on Savonius Rotors, Journal of Wind Engineering and Industrial Aerodynamics, Vol. 40, No. 3, pp. 277-292.

Holman, J. P., 2012, Experimental Methods for Engineers, 8th Edition, McGraw-Hill, New York, USA.

Kamoji, M. A., Kedare, S. B., and Prabhu, S. V., 2008, Experimental Investigations on Single Stage, Two-Stage and Three Stage Conventional Savonius Rotor, International Journal of Energy Research, Vol. 32, pp. 877-895.

Kamoji, M. A., Kedare, S. B., and Prabhu, S. V., 2009, Experimental Investigations on Single Stage Modified Savonius Rotor, Applied Energy, Vol. 86, pp. 1064-1073.

Kline, S. J., and McClintock, F. A., 1953, Describing the Uncertainties in Single Sample Experiments, Mechanical Engineering, pp. 3-8.

Menet, J. L., and Bourabaa, N., 2004, Increase in the Savonius Rotors Efficiency via a Parametric Investigation, in: European Wind Energy Conference, London.

Menter, F. R., Kuntz, M., and Langtry, R., 2003, Ten Years of Industrial Experience with the SST Turbulence Model, Turbulence Heat and Mass Transfer, Vol. 4, pp. 625-632.

Patankar, S. V., 1980, Numerical Heat Transfer and Fluid Flows, McGraw-Hill, New York, USA.

Roache, P. J., 1994, Perspective: a Method for Uniform Reporting of Grid Refinemente Studies, Journal of Fluids Engineering, Vol. 116, pp. 405-413.

Saha, U. K., Thotla, S., and Maity, D., 2008, Optimum Design Configuration of Savanius Rotor though Wind Tunnel Experiments, Journal of Wind Engineering and Industrial Aerodynamics, Vol. 96, pp. 1359-1375.

Savonius, S. J., 1930, Wind Rotor - Patent Number 1,766,765, United States Patent Office.

Wilcox, D. C., 1998, Turbulence Modeling for $C F D$, DCW Industries, Inc. 